\title{
Organocatalyzed Group Transfer Polymerization of Alkyl \\ Sorbate: Polymer Synthesis, Post-polymerization Modification and Thermal Properties
}

\author{
Yujian Liu, Yanping Li, Yougen Chen*

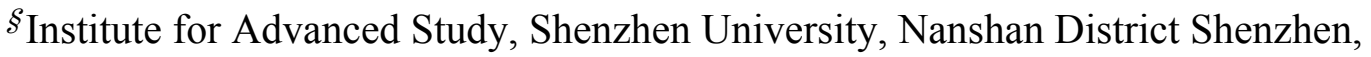 \\ Guangdong, 518060, China
}

CORRESPONDING AUTHOR FOOTNOTE

Tel \& Fax: +86-75526943283.

E-mail: chenyg@szu.edu.cn 


\section{Experimental Section}

Synthesis of $\boldsymbol{n}$-alkyl sorbate. DCC $\left(12.38 \mathrm{~g}, 0.06 \mathrm{~mol}\right.$, dissolved in $\left.50 \mathrm{~mL} \mathrm{CH}_{2} \mathrm{Cl}_{2}\right)$ was added slowly to a mixed solution of sorbic acid (5.61 g, $0.05 \mathrm{~mol})$, corresponding alkanol $(0.06 \mathrm{~mol})$ and DMAP $(0.61 \mathrm{~g}, 50 \mathrm{mmol})$ in $\mathrm{CH}_{2} \mathrm{Cl}_{2}(100 \mathrm{~mL})$ under an argon atmosphere at $0{ }^{\circ} \mathrm{C}$. The solution was then allowed to warm up to room temperature and stirred for overnight. The reaction mixture was filtered and washed with $1 \mathrm{M} \mathrm{HCl}$ $(100 \mathrm{~mL})$, conc. $a q . \mathrm{NaHCO}_{3}(100 \mathrm{~mL})$, distilled water $(100 \mathrm{~mL})$. The organic layer was then dried over anhydrous $\mathrm{Na}_{2} \mathrm{SO}_{4}$, filtered and concentrated under vacuum.

For hexyl sorbate, the crude product was gone through silica gel chromatography (n-hexane-EtOAc (v/v), 20:1) to give a light yellow oil (Yield, $6.41 \mathrm{~g}, 65 \%) .{ }^{1} \mathrm{H}$ NMR $\left(500 \mathrm{MHz}, \mathrm{CDCl}_{3}\right) \delta 7.25\left(\mathrm{dd}, J=15.3,10.2 \mathrm{~Hz}, \mathrm{CH}_{3} \mathrm{CH}=\mathrm{CHCH}=\mathrm{CH}, 1 \mathrm{H}\right), 6.24-$ $6.08\left(\mathrm{~m}, \mathrm{CH}_{3} \mathrm{C} \underline{\mathrm{H}}=\mathrm{C} \underline{\mathrm{HCH}}=\mathrm{CH}, 2 \mathrm{H}\right), 5.78\left(\mathrm{~d}, J=15.4 \mathrm{~Hz}, \mathrm{CH}_{3} \mathrm{CH}=\mathrm{CHCH}=\mathrm{C} \underline{\mathrm{H}}, 1 \mathrm{H}\right)$, $4.13\left(\mathrm{t}, J=6.8 \mathrm{~Hz}, \mathrm{CO}_{2} \mathrm{CH}_{2}, 2 \mathrm{H}\right), 1.85\left(\mathrm{~d}, J=6.1 \mathrm{~Hz}, \mathrm{C}_{3} \mathrm{CH}=\mathrm{CH}, 3 \mathrm{H}\right), 1.70-1.61$ (m, $\left.\mathrm{CH}_{2}, 2 \mathrm{H}\right), 1.42-1.24\left(\mathrm{~m}, \mathrm{CH}_{2}, 6 \mathrm{H}\right), 0.89$ (t, $\left.J=7.0 \mathrm{~Hz}, \mathrm{CH}_{2} \mathrm{CH}_{3}, 3 \mathrm{H}\right)$.

For $n$-octadecyl sorbate, the crude product was purified by reprecipitation in methanol three times to give white powders (Yield, 9.70g, $53 \%$ ). ${ }^{1} \mathrm{H}$ NMR (500 MHz, $\mathrm{CDCl}_{3}$ ) $\delta$ $7.24\left(\mathrm{dd}, J=15.4,10.4 \mathrm{~Hz}, \quad \mathrm{CH}_{3} \mathrm{CH}=\mathrm{CHC} \underline{\mathrm{H}}=\mathrm{CH}, 1 \mathrm{H}\right), 6.23-6.09$ (m, $\left.\mathrm{CH}_{3} \mathrm{C} \underline{\mathrm{H}}=\mathrm{C} \underline{\mathrm{HCH}}=\mathrm{CH}, 2 \mathrm{H}\right), 5.77\left(\mathrm{~d}, J=15.4 \mathrm{~Hz}, \mathrm{CH}_{3} \mathrm{CH}=\mathrm{CHCH}=\mathrm{C} \underline{\mathrm{H}}, 1 \mathrm{H}\right), 4.12(\mathrm{t}, J=$ $\left.6.8 \mathrm{~Hz}, \mathrm{CO}_{2} \mathrm{CH}_{2}, 2 \mathrm{H}\right), 1.85\left(\mathrm{~d}, J=6.3 \mathrm{~Hz}, \mathrm{CH}_{3} \mathrm{CH}=\mathrm{CH}, 3 \mathrm{H}\right), 1.69-1.61\left(\mathrm{~m}, \mathrm{CH}_{2}\right.$, $2 \mathrm{H}), 1.39-1.20\left(\mathrm{~m}, \mathrm{CH}_{2}, 30 \mathrm{H}\right), 0.88\left(\mathrm{t}, J=7.0 \mathrm{~Hz}, \mathrm{CH}_{2} \mathrm{CH}_{3}, 3 \mathrm{H}\right)$.

HS and ODS were dried under vacuum before polymerization. 

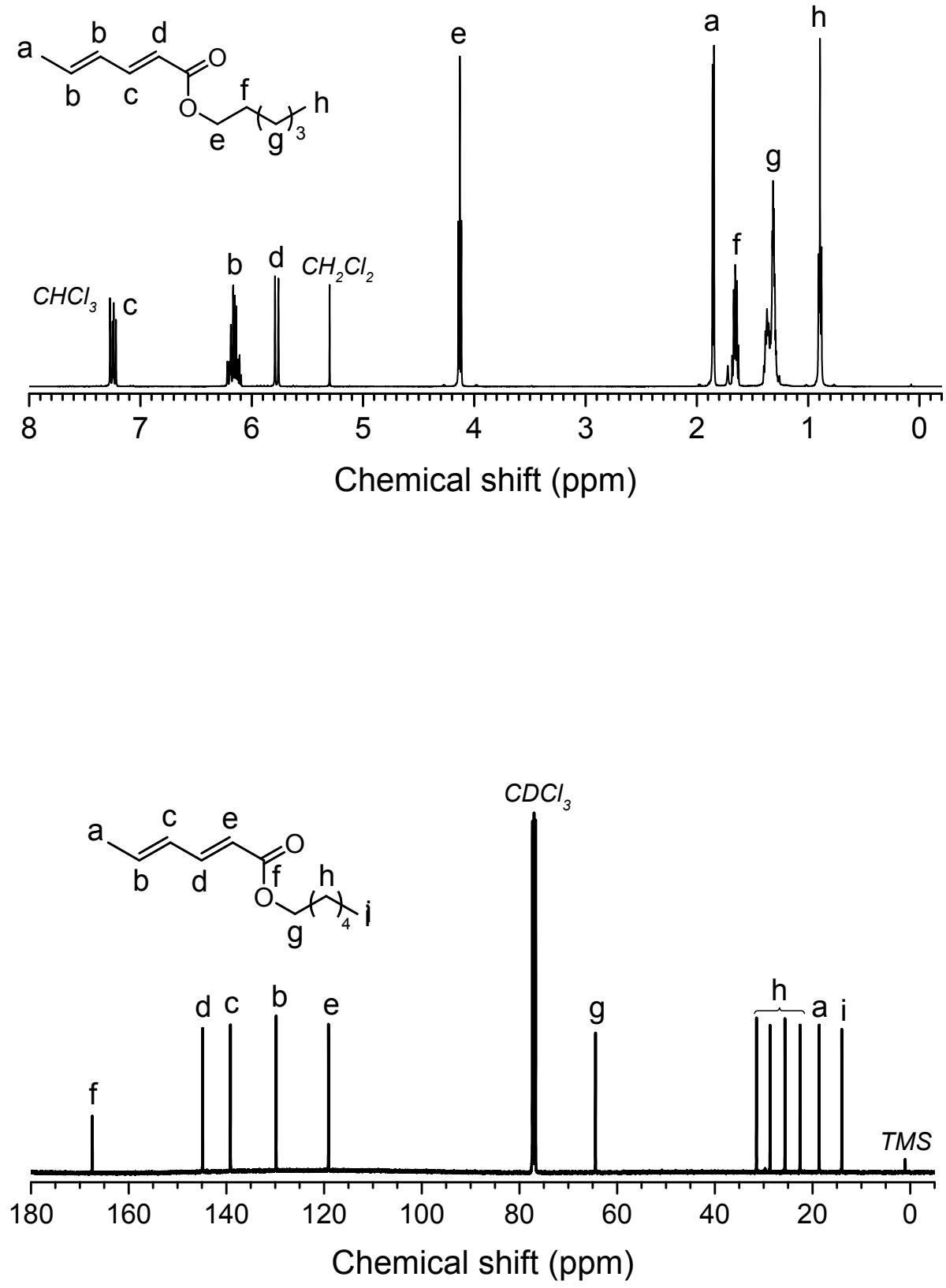

Figure S1. ${ }^{1} \mathrm{H}$ (above) and ${ }^{13} \mathrm{C}$ NMR spectra of $n$-hexyl sorbate in $\mathrm{CDCl}_{3}$. 

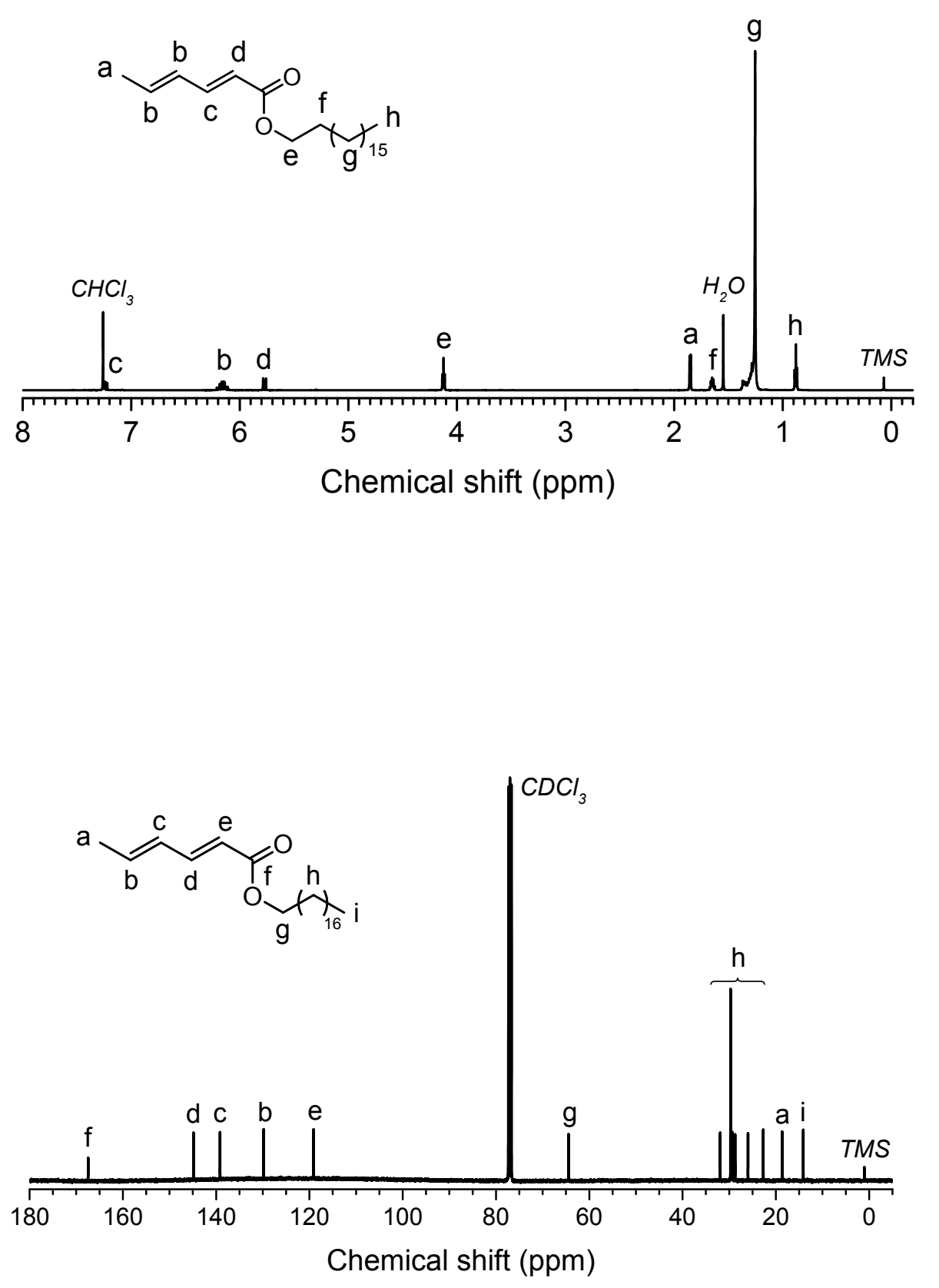

Figure S2. ${ }^{1} \mathrm{H}$ (above) and ${ }^{13} \mathrm{C}$ NMR spectra of $n$-octadecyl sorbate in $\mathrm{CDCl}_{3}$. 


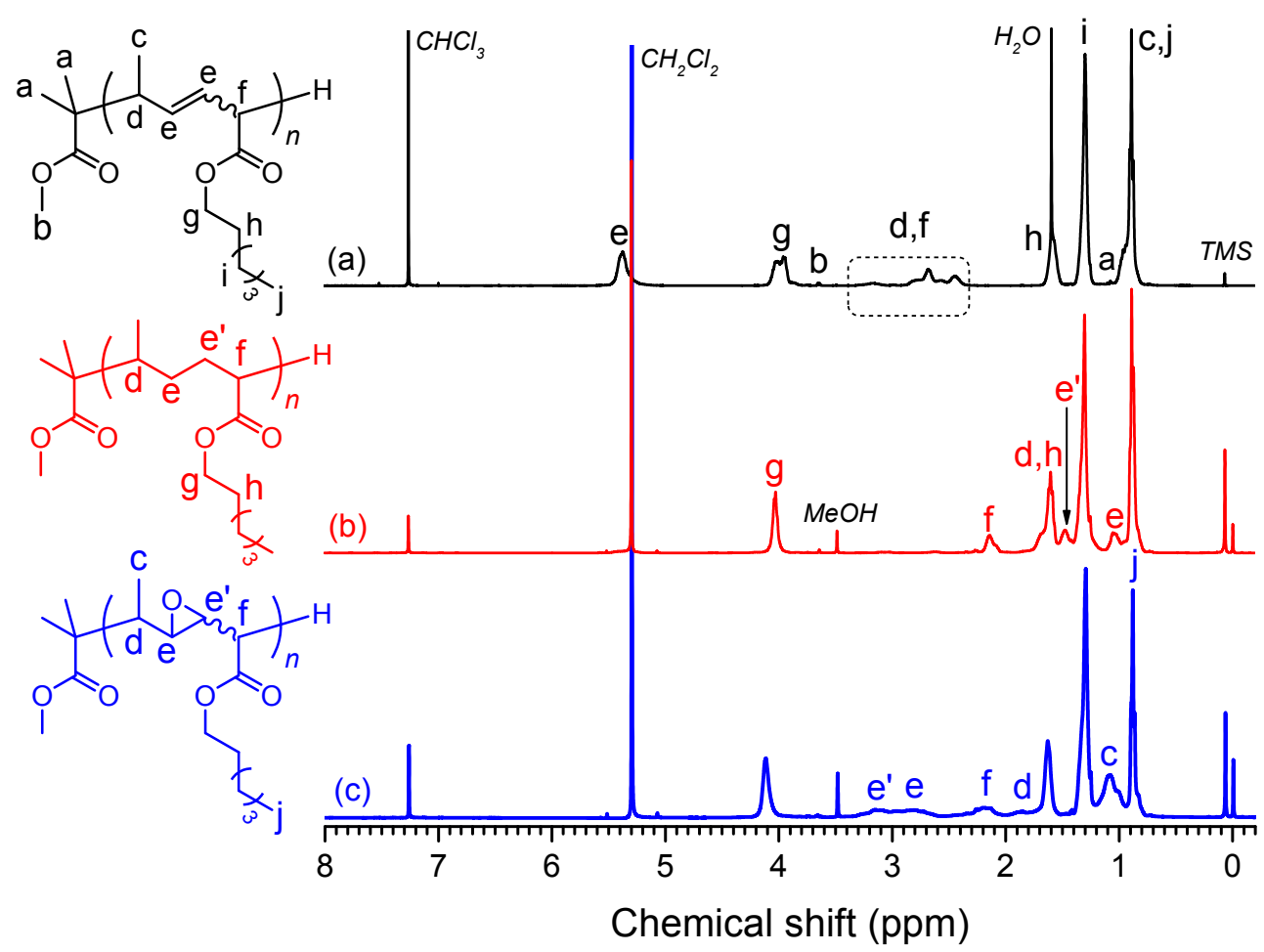

Figure S3. ${ }^{1} \mathrm{H}$ NMR spectra of (a) $\mathrm{PHS}_{100}$, (b) $\mathrm{PHS}_{100}-\mathrm{H}_{2}$, and (c) $\mathrm{PHS}_{100}$-epoxy in $\mathrm{CDCl}_{3}$. 


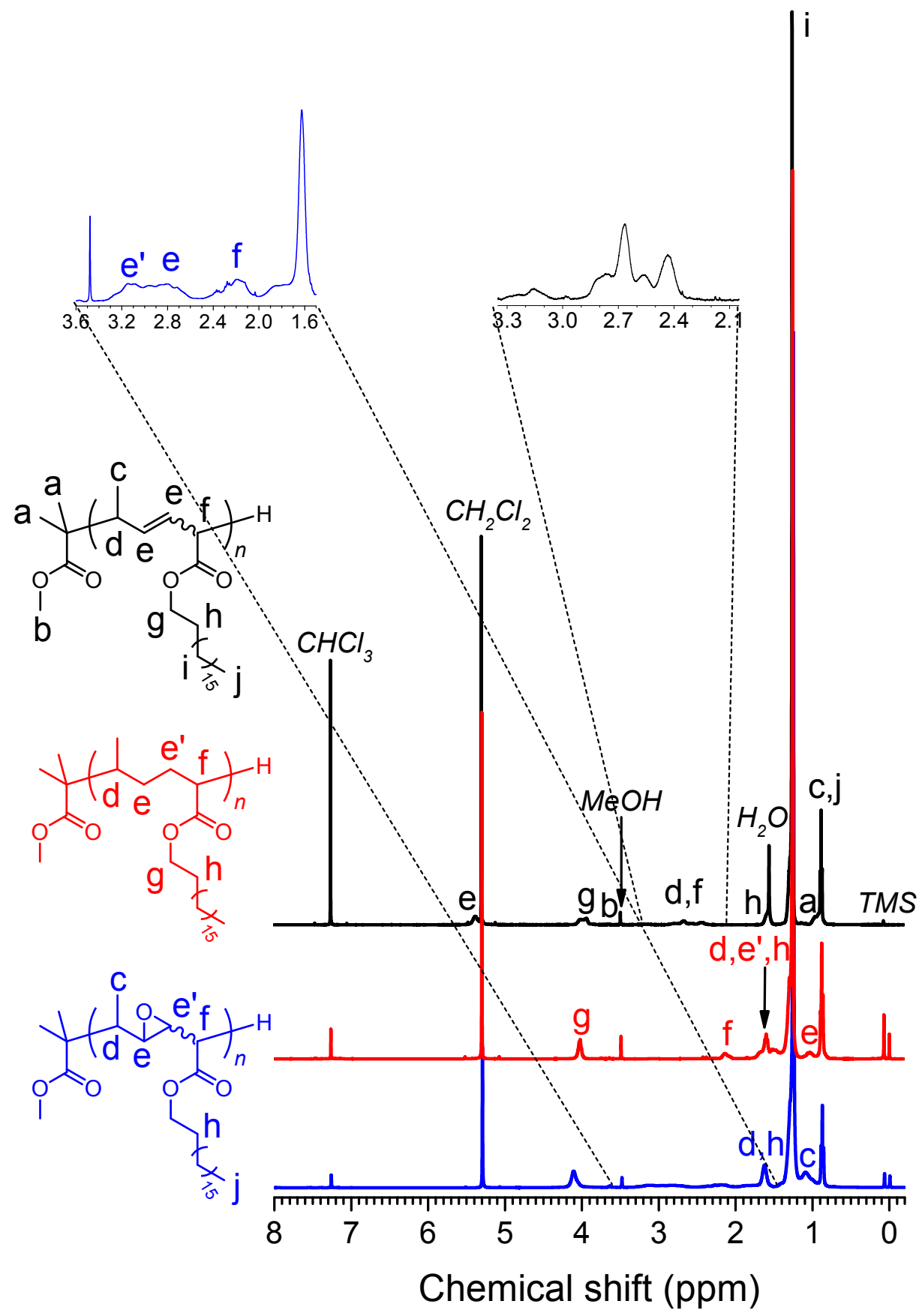

Figure S4. ${ }^{1} \mathrm{H}$ NMR spectra of (a) $\operatorname{PODS}_{100}$, (b) $\mathrm{PODS}_{100}-\mathrm{H}_{2}$, and (c) $\mathrm{PODS}_{100}$-epoxy in $\mathrm{CDCl}_{3}$. 


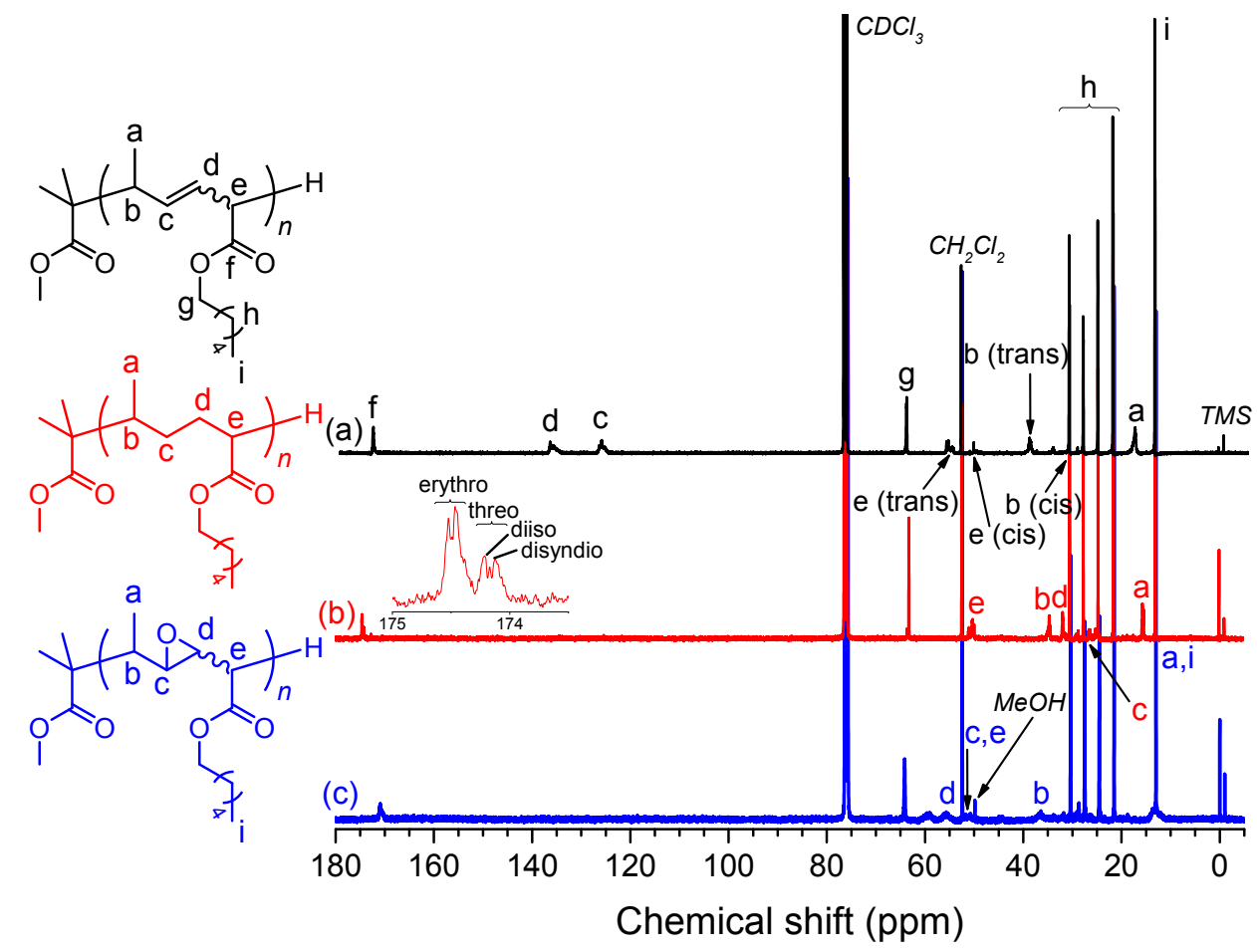

Figure S5. ${ }^{13} \mathrm{C}$ NMR spectra of (a) $\mathrm{PHS}_{100}$, (b) $\mathrm{PHS}_{100}-\mathrm{H}_{2}$, and (c) $\mathrm{PHS}_{100}$-epoxy in $\mathrm{CDCl}_{3}$. 


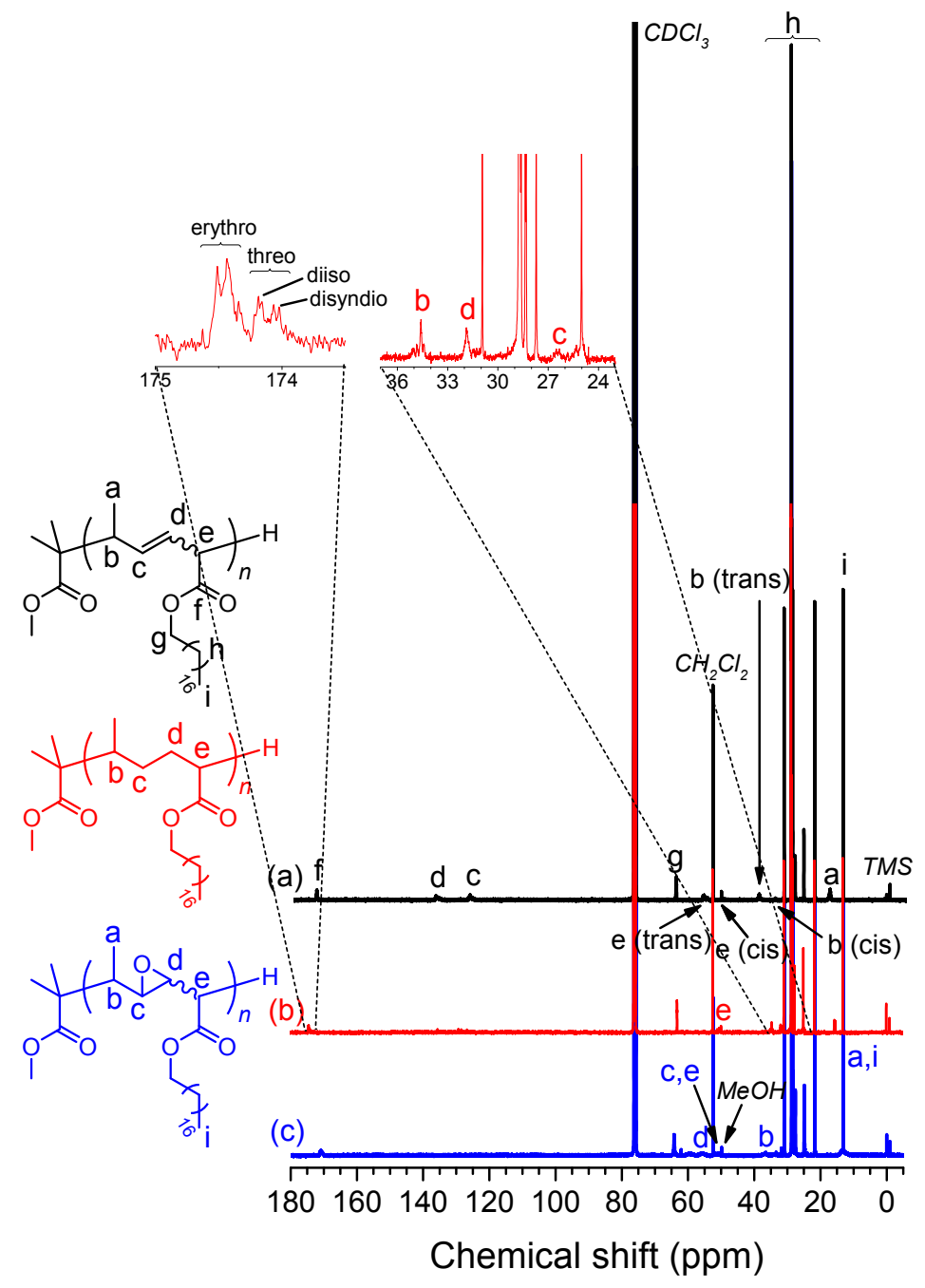

Figure S6. ${ }^{13} \mathrm{C}$ NMR spectra of (a) $\mathrm{PODS}_{100}$, (b) $\mathrm{PODS}_{100}-\mathrm{H}_{2}$, and (c) $\mathrm{PODS}_{100}$-epoxy in $\mathrm{CDCl}_{3}$. 

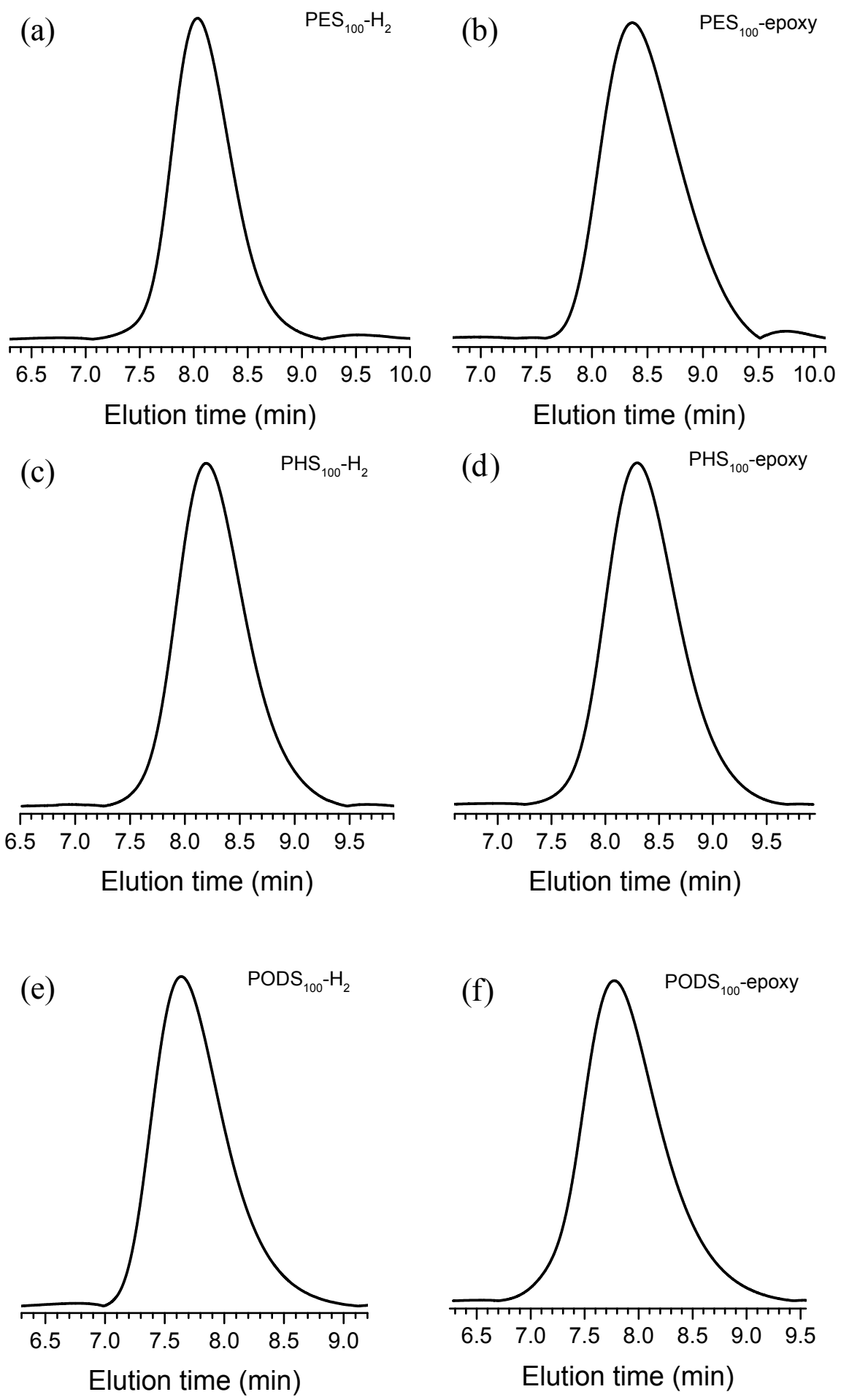

Figure S7. SEC traces of (a) $\mathrm{PES}_{100}-\mathrm{H}_{2}$, (b) $\mathrm{PES}_{100}$-epoxy, (c) $\mathrm{PHS}_{100}-\mathrm{H}_{2}$, (d) $\mathrm{PHS}_{100}$-epoxy, (e) $\mathrm{PODS}_{100}-\mathrm{H}_{2}$, and (f) $\mathrm{PODS}_{100}$-epoxy determined at $40{ }^{\circ} \mathrm{C}$ in $\mathrm{THF}$ by a SEC equipped with a refractive index detector at a flow rate of $0.35 \mathrm{~mL} \mathrm{~min}^{-1}$ on the basis of a polystyrene calibration. 


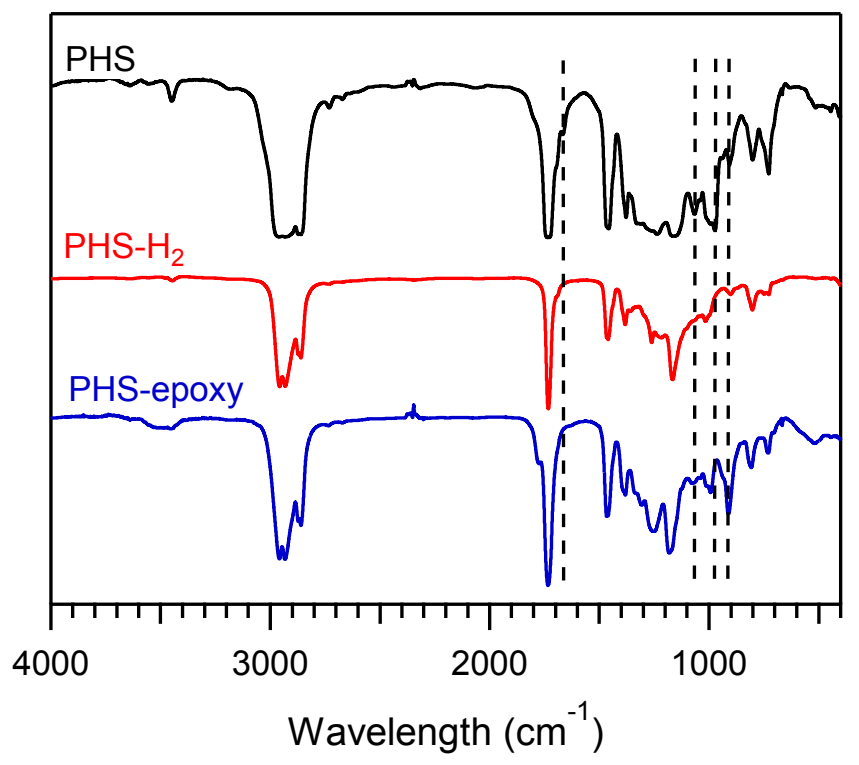

Figure S8. FT-IR spectra of $\mathrm{PHS}_{100}$ (black), $\mathrm{PHS}_{100}-\mathrm{H}_{2}$ (red), and $\mathrm{PHS}_{100}$-epoxy (blue).

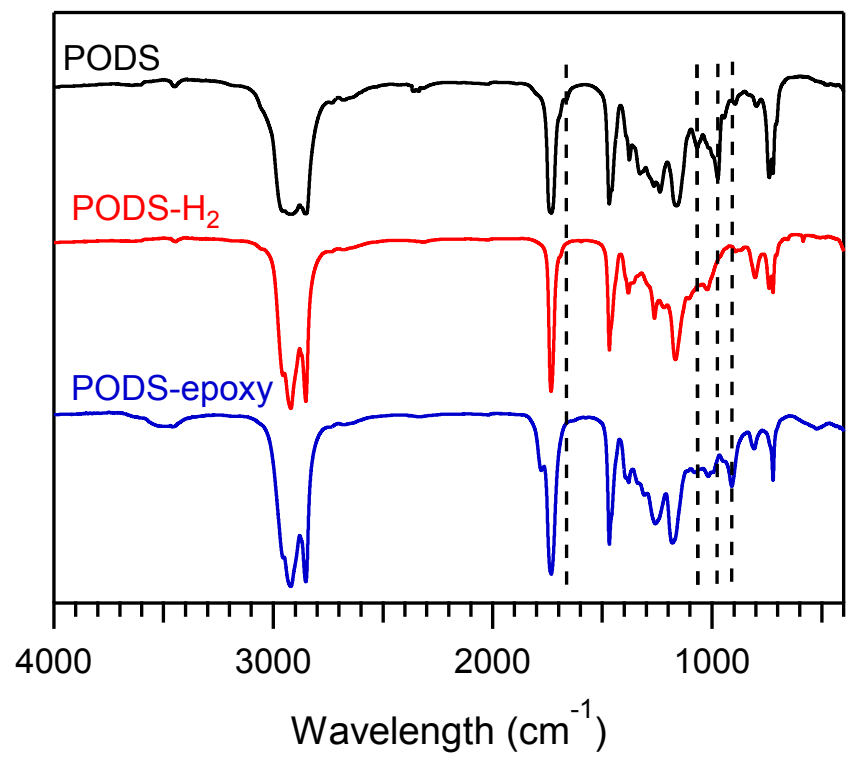

Figure S9. FT-IR spectra of PODS 100 (black), PODS $100-\mathrm{H}_{2}$ (red), and PODS 100 -epoxy (blue). 

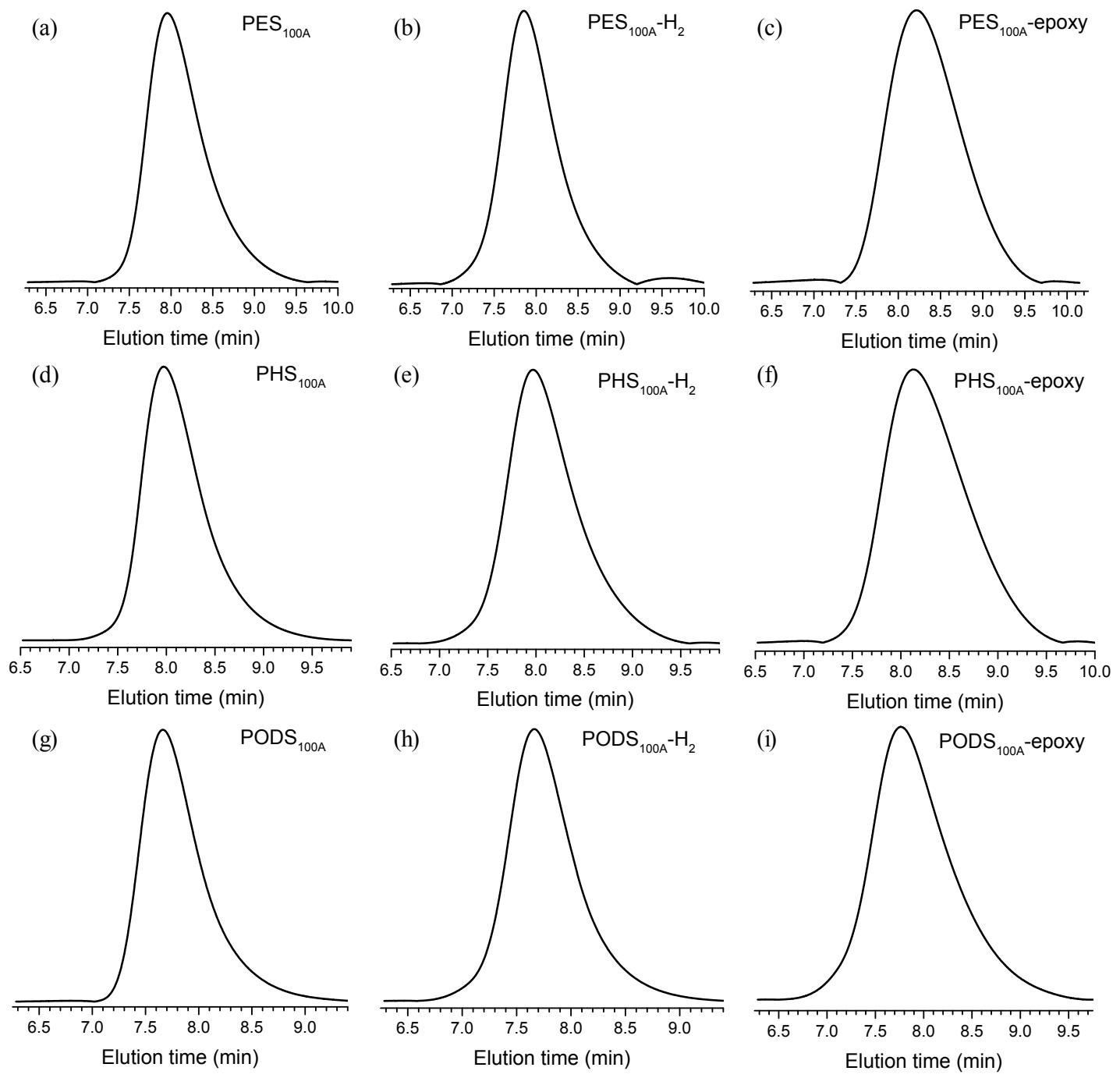

Figure S10. SEC traces of (a) $\mathrm{PES}_{100 \mathrm{~A}}$, (b) $\mathrm{PES}_{100 \mathrm{~A}}-\mathrm{H}_{2}$, (c) $\mathrm{PES}_{100 \mathrm{~A}}$-epoxy, (d) PHS $_{100 \mathrm{~A}}$, (e) $\mathrm{PHS}_{100 \mathrm{~A}}-\mathrm{H}_{2}$, (f) $\mathrm{PHS}_{100 \mathrm{~A}}$-epoxy, (g) PODS $100 \mathrm{~A}-\mathrm{H}_{2}$, (h) PODS $100 \mathrm{~A}$-epoxy, and (i) PODS $100 \mathrm{~A}^{-e p o x y}$ determined at $40{ }^{\circ} \mathrm{C}$ in THF by a SEC equipped with a refractive index detector at a flow rate of $0.35 \mathrm{~mL} \mathrm{~min}^{-1}$ on the basis of a polystyrene calibration. 


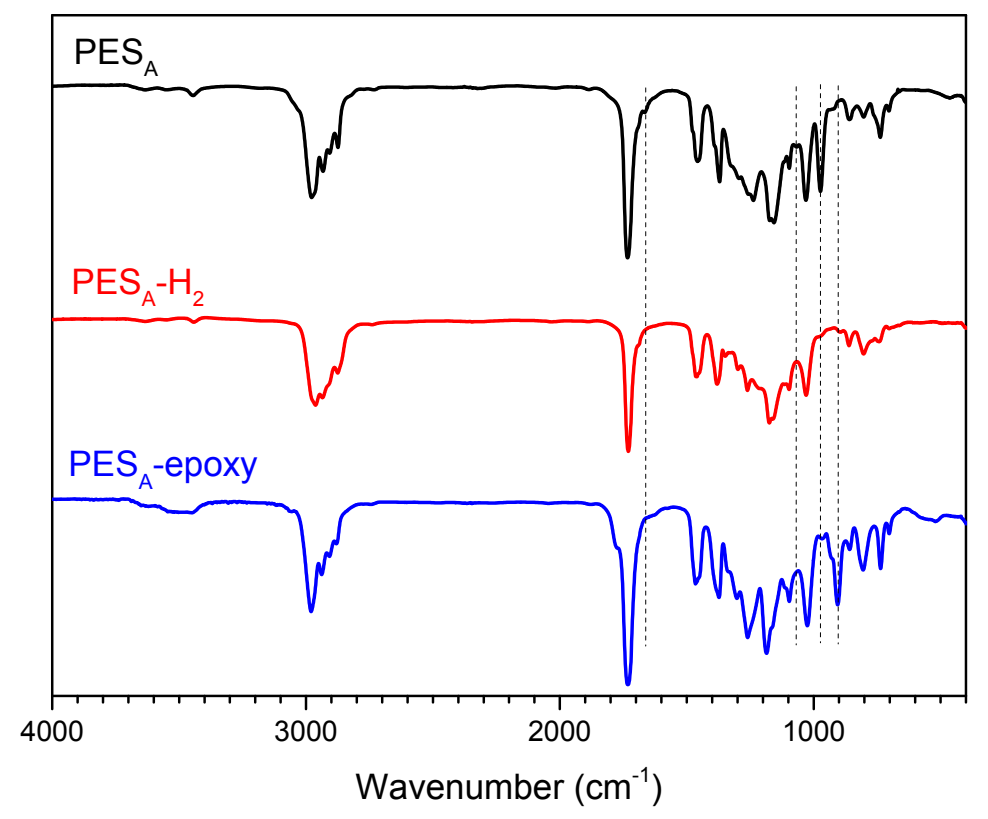

Figure S11. FT-IR spectra of $\mathrm{PES}_{100 \mathrm{~A}}$ (black), $\mathrm{PES}_{100 \mathrm{~A}}-\mathrm{H}_{2}$ (red), and $\mathrm{PES}_{100 \mathrm{~A}}$-epoxy (blue).

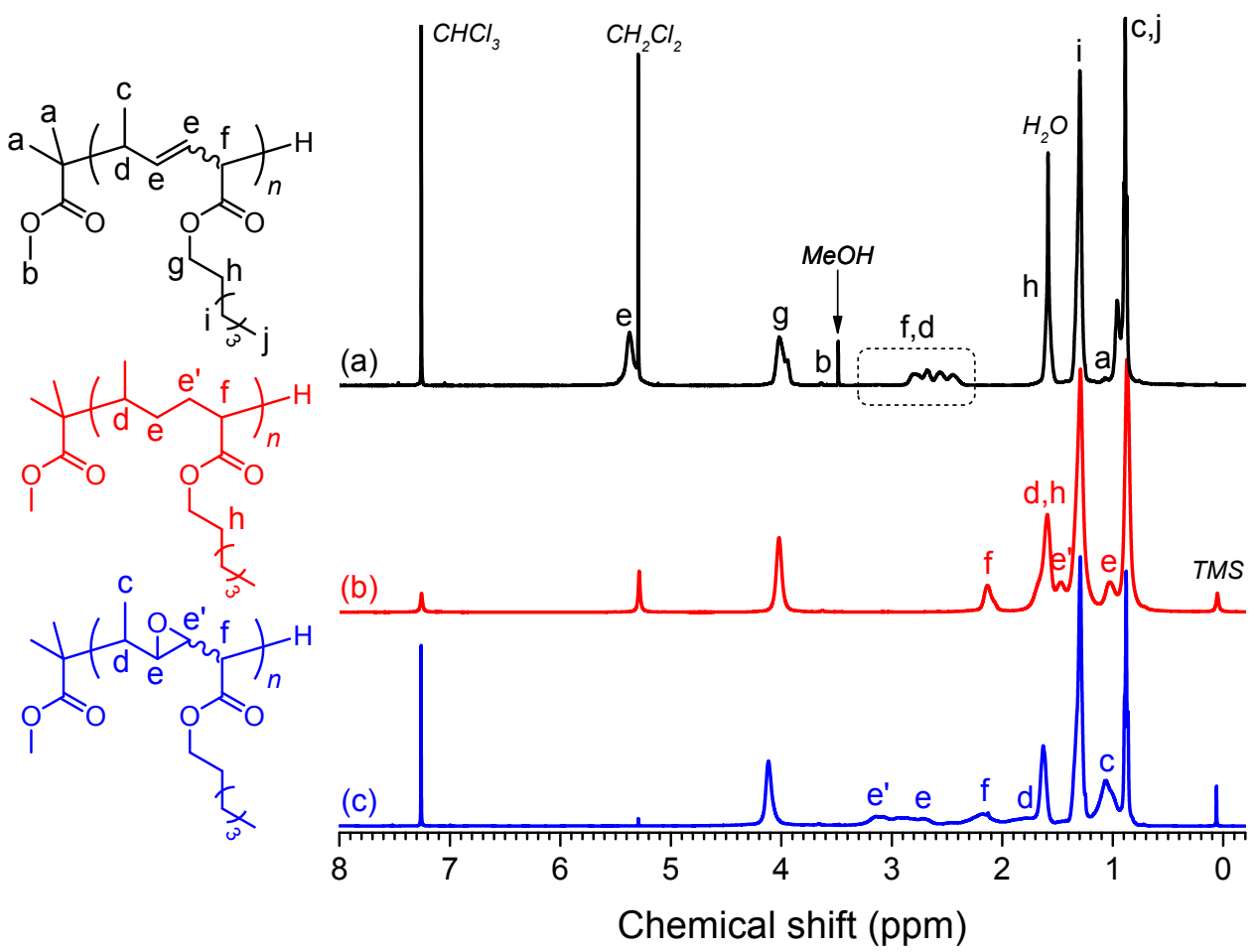

Figure S12. ${ }^{1} \mathrm{H}$ NMR spectra of (a) $\mathrm{PHS}_{100 \mathrm{~A}}$, (b) $\mathrm{PHS}_{100 \mathrm{~A}}-\mathrm{H}_{2}$, and (c) $\mathrm{PHS}_{100 \mathrm{~A}}$-epoxy in $\mathrm{CDCl}_{3}$. 


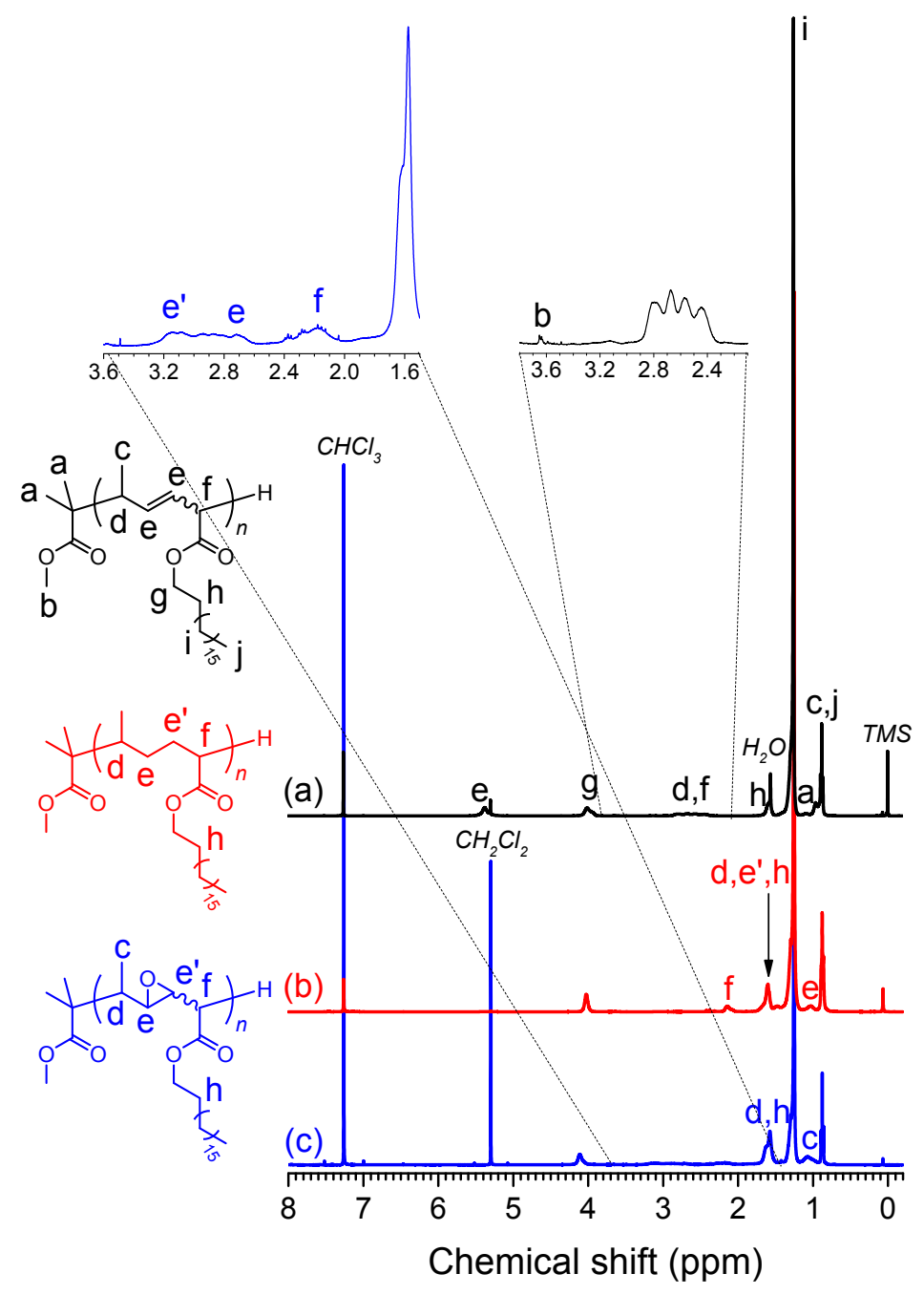

Figure S13. ${ }^{1} \mathrm{H}$ NMR spectra of (a) $\mathrm{PODS}_{100 \mathrm{~A}}$, (b) $\mathrm{PODS}_{100 \mathrm{~A}}-\mathrm{H}_{2}$, and (c) $\operatorname{PODS}_{100 \mathrm{~A}}$-epoxy in $\mathrm{CDCl}_{3}$. 


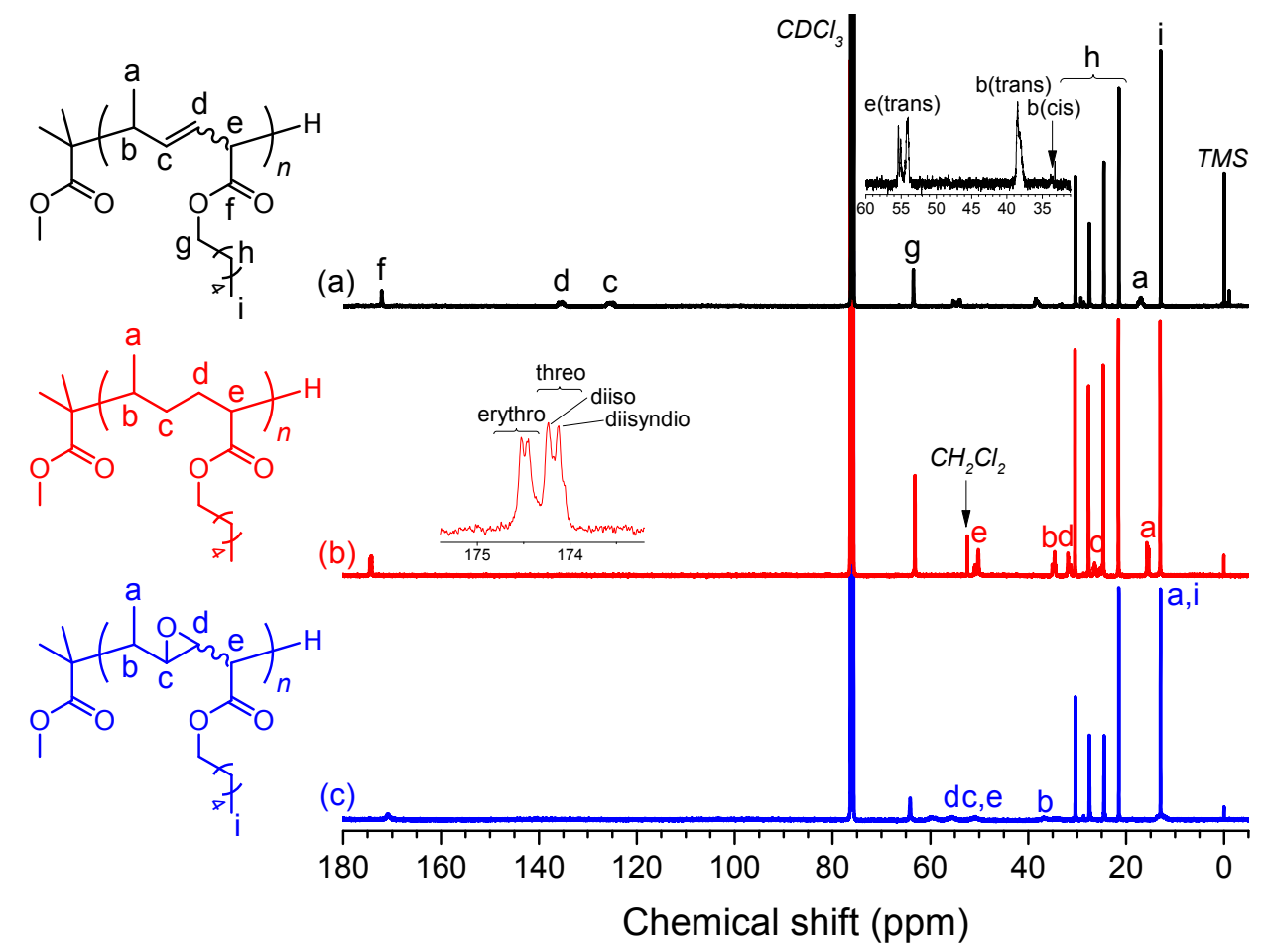

Figure S14. ${ }^{13} \mathrm{C}$ NMR spectra of (a) $\mathrm{PHS}_{100 \mathrm{~A}}$, (b) $\mathrm{PHS}_{100 \mathrm{~A}}-\mathrm{H}_{2}$, and (c) $\mathrm{PHS}_{100 \mathrm{~A}}$-epoxy in $\mathrm{CDCl}_{3}$. 


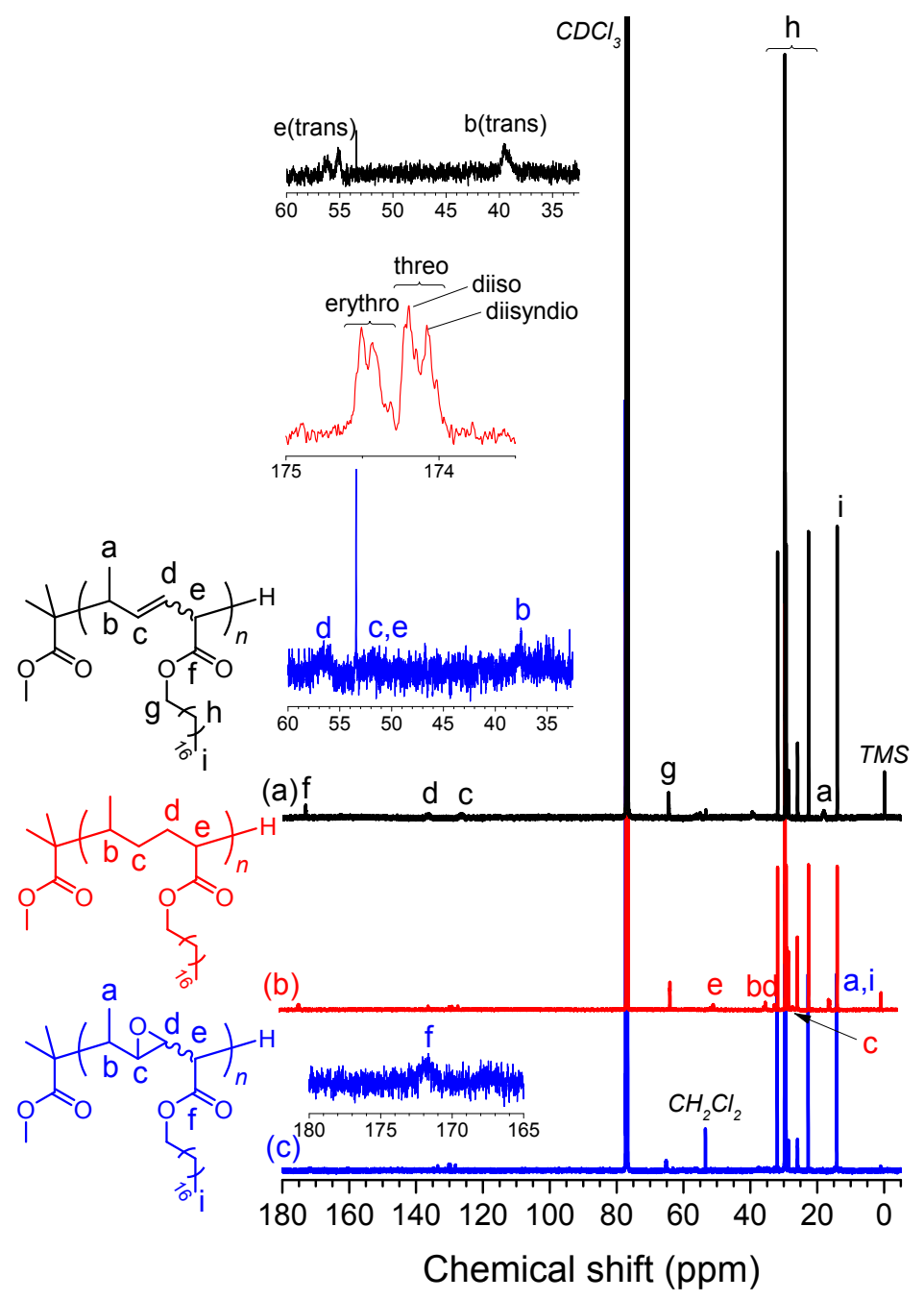

Figure S15. ${ }^{13} \mathrm{C}$ NMR spectra of (a) $\mathrm{PODS}_{100 \mathrm{~A}}$, (b) $\mathrm{PODS}_{100 \mathrm{~A}}-\mathrm{H}_{2}$, and (c) PODS $100 \mathrm{~A}$-epoxy in $\mathrm{CDCl}_{3}$. 

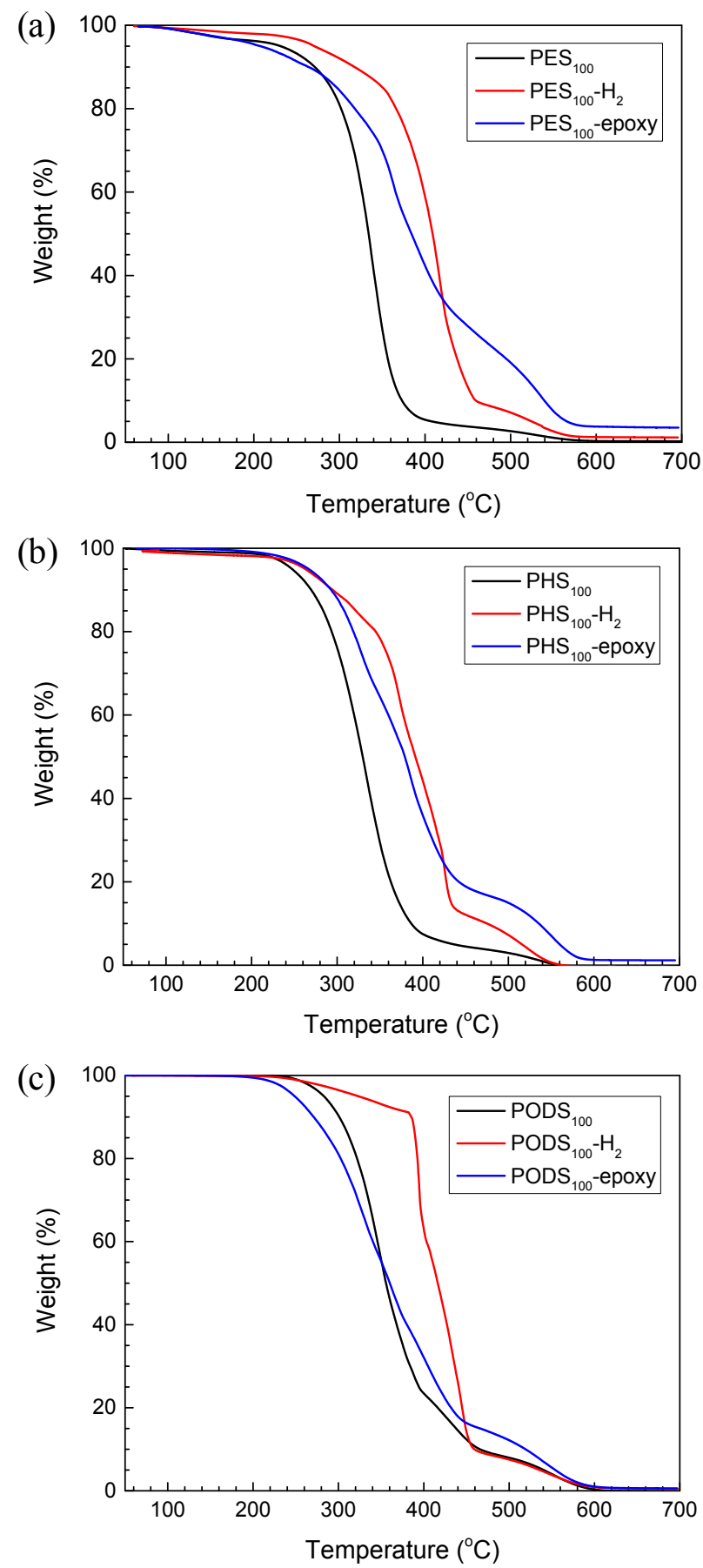

Figure S16. Thermogravimetric diagrams of (a) $\mathrm{PES}_{100}, \mathrm{PES}_{100}-\mathrm{H}_{2}$, and PES $_{100}$-epoxy, (b) $\mathrm{PHS}_{100}, \mathrm{PHS}_{100}-\mathrm{H}_{2}$, and $\mathrm{PHS}_{100}$-epoxy, and (c) PODS 100 , $\operatorname{PODS}_{100}-\mathrm{H}_{2}$, and PODS 100 -epoxy. 

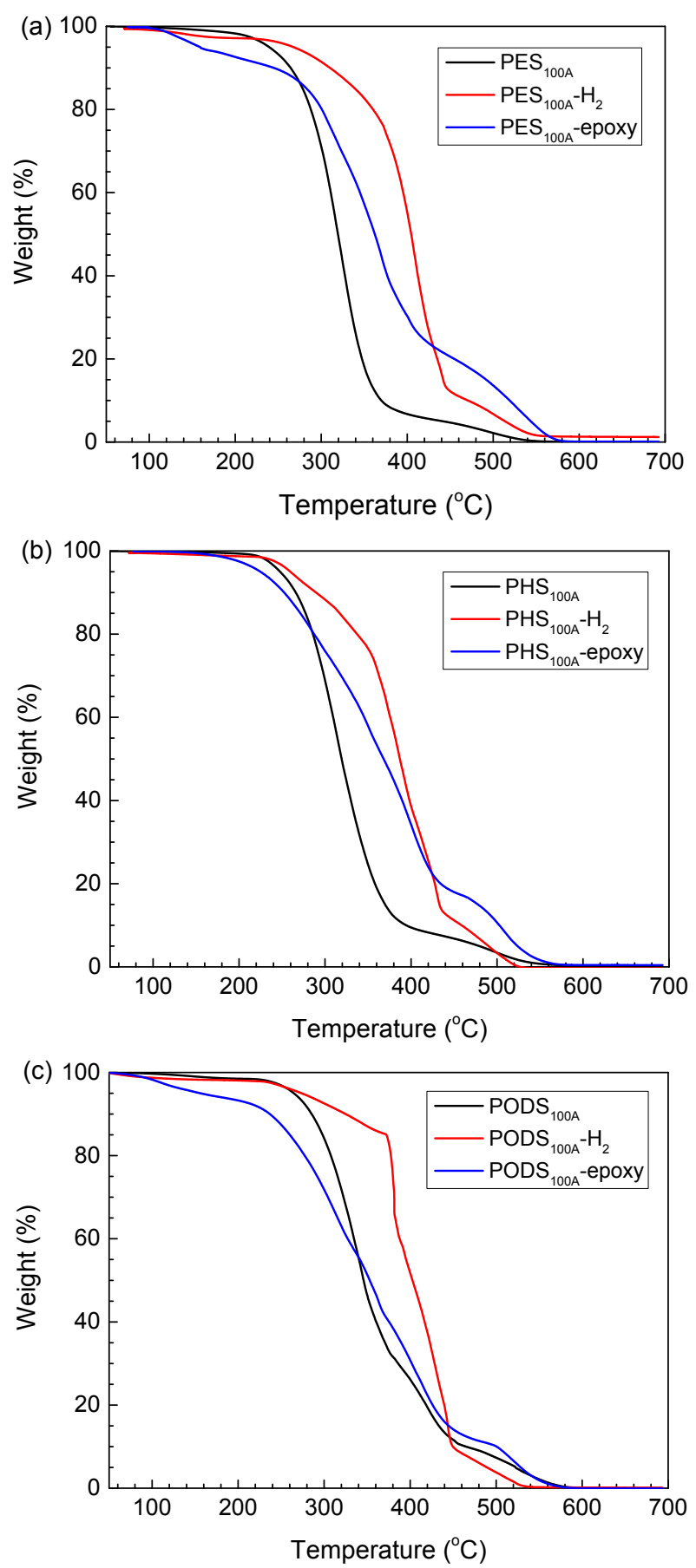

Figure S17. Thermogravimetric diagrams of (a) $\mathrm{PES}_{100 \mathrm{~A}}, \mathrm{PES}_{100 \mathrm{~A}}-\mathrm{H}_{2}$, and PES $100 \mathrm{~A}$-epoxy, (b) $\mathrm{PHS}_{100 \mathrm{~A}}, \mathrm{PHS}_{100 \mathrm{~A}}-\mathrm{H}_{2}$, and $\mathrm{PHS}_{100 \mathrm{~A}}$-epoxy, and (c) PODS $100 \mathrm{~A}$, PODS $_{100 \mathrm{~A}}-\mathrm{H}_{2}$, and PODS $_{100 \mathrm{~A}}$-epoxy. 